\title{
Antiatherogenic effects of vitamin E: the search for the Holy Grail
}

\author{
This article was published in the following Dove Press journal: \\ Vascular Health and Risk Management \\ 9 September 2009 \\ Number of times this article has been viewed
}

\section{Dimitrios Kirmizis \\ Dimitrios Chatzidimitriou}

Aristotle University, Thessaloniki, Greece
Correspondence: Dimitrios Kirmizis Karavangeli 19 str, 55 I34, Kalamaria,

Thessaloniki, Greece

Tel +30 6973668833

$\mathrm{Fax}+302351035555$

Email dkirmizis@yahoo.co.uk

\begin{abstract}
Vitamin E, a naturally occurring antioxidant, has been found to reduce atherosclerotic lesion formation in animal models as well as cardiovascular morbidity in several observational studies. However, a number of case-control and prospective cohort studies failed to confirm its value in the primary and secondary prevention of morbidity and mortality from coronary artery disease. Several small or larger randomized interventional trials completed to date failed to resolve the conflict. Notably, even in large, well-conducted prospective epidemiologic studies, the potential effects of residual confounding may be on the same order of magnitude as the reported benefit. The response to vitamin E supplementation in specific patient subpopulations with chronic inflammation and/or higher degrees of oxidative stress has not been studied as yet. Therefore, further large randomized interventional trials are warranted to clarify accurately the role of vitamin $\mathrm{E}$ in the primary and secondary prevention of atherosclerotic coronary disease in these patient groups.
\end{abstract}

Keywords: antioxidant, anti-inflammatory, vitamin E, atherosclerosis, cardiovascular disease

\section{Introduction}

Oxidative modification of low-density lipoprotein is an important step in the development and progression of atherosclerosis in experimental studies, ${ }^{1}$ and antioxidants such as vitamin $\mathrm{E}$ have been shown to slow atherosclerosis. ${ }^{2,3}$ An inverse relation has been observed between coronary heart disease and the consumption of fruits, vegetables, and other foods containing vitamins, particularly vitamin $\mathrm{E}$ as well as the concentrations of $\alpha$-tocopherol $(\alpha-T) .^{4-7}$ Observational studies have indicated that persons who consume more than $100 \mathrm{IU}$ of $\alpha$-T per day for more than two years have lower rates of coronary events and lower rates of progression of coronary artery lesions. ${ }^{4,8-11}$ However, observational studies cannot prove a genuine etiologic relation between the lower risk of coronary heart disease and $\alpha$-T consumption. Despite this, randomized, controlled trials of antioxidant vitamins in cardiovascular disease have thus far yielded largely conflicting results ${ }^{12-17}$ for reasons discussed further below. We provide herein an update of the literature on this issue and discuss the existing data from $\alpha$-T supplementation studies in the general population as well as the data from the use of vitamin-E coated dialyzers in end-stage renal disease (ESRD) patients, which we believe add further information on the antiatherogenic effects of $\alpha$-T.

\section{Mechanisms of action}

Vitamin $\mathrm{E}$ is consisted of a group of eight fat-soluble complexes, namely $\alpha-, \beta-, \gamma-$, and $\delta$-tocopherols as well as $\alpha$-, $\beta$-, $\gamma$-, and $\delta$-tocotrienoles. Commercially available forms contain vitamin $\mathrm{E}$ as the natural RRR- $\alpha$-tocopherol (RRR- $\alpha-T)$, as the synthetic 
$\alpha$-tocopherol (rac- $\alpha-T)$, or as a mixture of both. Different vitamin $\mathrm{E}$ complexes have different bioavailability, the $\alpha-\mathrm{T}$ being preferentially transferred by $\alpha$-tocopherol transfer protein $(\alpha$-TTP) into plasma lipoproteins (high-density lipoprotein [HDL] and low-density lipoprotein [LDL]), forming a complex which protects them from peroxidation by free radicals. This difference in bioavailability between different vitamin E complexes confers special functional capacities in $\alpha$-T compared to other tocopherols and tocotrienols. In the molecular level, the central role of vitamin $\mathrm{E}$ in the protection against lipid peroxidation is exerted through its function as hydrogen donor to lipid peroxide radicals. One major category of actions of oral supplementation with $\alpha-\mathrm{T}$ is related to the increase in the resistance of LDL to oxidation and the decrease in the cytotoxicity of oxidized LDL toward endothelial cells, which is known to play a pivotal role in the atherogenetic process. ${ }^{18,19}$ In brief, enhanced protection of LDL against oxidation is associated with a number of vascular effects that would be expected to reduce the clinical activity of coronary artery disease: reduced plaque rupture, platelet adhesion, and vasospasm. Beyond the protection against LDL oxidation, $\alpha-T$ converts in parallel multiple other actions (Table 1), such as the inhibition of smooth muscle cell proliferation, the maintenance of normal endothelial cell function, the decrease in the levels of soluble adhesion molecules and inhibition of monocyteendothelial cell adhesion, inhibition of monocyte release of reactive oxygen species (ROS) and inflammatory cytokines (interleukin-1 $\beta$ [IL-1 $\beta$ ], interleukin-6 [IL-6], tumor necrosis factor- $\alpha[$ TNF- $\alpha]$ ), the decrease in the levels of soluble platelet activation inhibitor-1 (PAI-1), and inhibition of platelet adhesion and aggregation. Moreover, $\alpha$-T regulates signal transduction and gene expression in different cell pathways, through special interactions with enzymes such as protein kinase $\mathrm{C}$ and $\mathrm{B}$, protein phosphatase $2 \mathrm{~A}$, diacylglycerol kinase,

Table I Nonantioxidant and regulatory functions of vitamin E

Inhibition of smooth muscle cell proliferation

Maintenance of normal endothelial cell function

Decrease in the levels of soluble adhesion molecules

Inhibition of monocyte-endothelial cell adhesion

Inhibition of monocyte release of ROS and inflammatory cytokines

Decrease in the levels of soluble PAI- I

Inhibition of platelet adhesion and aggregation

Signal transduction regulation and gene expression in different cell pathways

Regulation of enzymes, transcription factors and receptors phospholipase $\mathrm{A}_{2}$, cycloxygenase 2 , and 5-lipoxygenase (5-LOX), structural proteins, lipids, and transcription factors. ${ }^{20}$ Furthermore, tocopherols affect certain enzymes, such as 3-hydroxy-3-methyl-glutaryl-CoA (HMG-CoA) reductase and cytochrome $\mathrm{P} 450$ enzymes, transcription factors and receptors, such as LDL receptors, scavenger receptors CD36 and BI, at a transcriptional level. Finally, antioxidative effects of $\alpha$-T themselves lead to a decrease in inflammation, through the increase in bioavailability of endothelial nitric oxide (NO), which suppresses of the expression of the genes of several inflammatory molecules, such as monocyte chemotactic protein-1 (MCP-1), P-selectin, and vascular cell adhesion molecule-1 (VCAM-1). ${ }^{21}$ Though several studies have supported slow progression and prevention of atherosclerosis with $\alpha-T,{ }^{22,23}$ the exact vasoprotective role of vitamin $\mathrm{E}$ is still evasive even though recent reports have questioned the role of vitamin $\mathrm{E}$ in the atherogenetic process. ${ }^{24,25}$

\section{Controversies of the clinical trials}

Epidemiological studies over the last years suggest that low levels of antioxidants are associated with increased risk for cardiovascular disease and that increased intakes appear to be protective. Moreover, several studies have revealed a relationship between antioxidant vitamins and early carotid artery atherosclerosis, determined by B-mode ultrasound measurement of carotid artery intima-media thickness (IMT). ${ }^{26,27}$ Despite the aforementioned evidence, there has been an unexpected discrepancy between the anticipated cardiovascular benefits and the results of major prospective primary and secondary prevention clinical trials. For example, in the Alpha-Tocopherol, Beta Carotene (ATBC) study, ${ }^{15}$ the incidence of myocardial infarction, cardiovascular events and cardiovascular mortality did not differ in participants randomly assigned to $\alpha-\mathrm{T}$ (50 IU/day) compared with those assigned to placebo. In the Heart Outcomes Prevention Evaluation (HOPE) Study, ${ }^{16}$ a double-blind, randomized trial conducted to evaluate the effects of ramipril and vitamin $\mathrm{E}$ (400 IU/day) in 9541 patients at high risk for cardiovascular events, it was found that treatment with vitamin $\mathrm{E}$ for a mean of 4.5 years had no apparent effect on cardiovascular outcomes. In the open-label, nonplacebo-controlled Primary Prevention Project $^{17}$ in the general population, $\alpha$-T supplementation (300 IU/day) for four years had no significant impact on the incidence of myocardial infarction, cardiovascular events, cardiovascular mortality or all-cause mortality, compared to controls. Of the major randomized controlled trials of $\alpha$-T supplementation for secondary prevention of cardiovascular events, Cambridge Heart Antioxidant Study (CHAOS) ${ }^{14}$ 
was the only one to describe a significantly reduced risk for myocardial infarction and all cardiac events after 1.5 years of $\alpha$-T supplementation. However, it was encumbered by design problems, including unbalanced randomization, incomplete follow-up, and a mid-study change in $\alpha$-T dose $(800 \mathrm{IU} / \mathrm{d}$ to $400 \mathrm{IU} / \mathrm{d}){ }^{28}$ In the largest of the secondary prevention trials, open-label, nonplacebo-controlled GISSI-P (Gruppo Italiano per lo Studio della Sopravvivenza n'nfarto miocardico-Prevenzione) study, combined primary and cardiovascular end points were not significantly reduced in the two-way or four-way analyses comparing $\alpha$-T supplements with no treatment. ${ }^{29}$ In secondary analyses, $\alpha$-T supplementation significantly reduced cardiovascular death, including cardiac, coronary, and sudden deaths, in the four-way but not the two-way analysis. The Secondary Prevention with Antioxidants of Cardiovascular disease in End-stage renal disease (ESRD) (SPACE) study ${ }^{30}$ was a double-blind, placebo-controlled, randomized, secondary prevention trial in hemodialysis patients. The primary endpoint was a composite variable consisting of myocardial infarction, ischemic stroke, peripheral vascular disease, and unstable angina. In addition to a significant increase in $\alpha$-T levels, RRR- $\alpha$-T (800 IU/d) significantly decreased the primary endpoint by $54 \%$. Finally, several meta-analyzes failed to confirm any significant benefit in primary or secondary cardiovascular prevention. . $^{31,32}$

\section{Confounding factors}

Even though the majority of the randomized trials have shown a significant reduction in cardiovascular endpoints, they failed in general to show parallel improvement in cardiovascular mortality, probably due to their insufficient statistical power to examine mortality as an endpoint. In the bottom line, there appears to be a potential 30\%-60\% reduction in cardiovascular endpoints with antioxidant therapy in the form of oral $\alpha$-T, the patient's level of risk as well as the dosing and duration of therapy being important factors. The discrepancy between the findings in the observational and intervention studies could be well attributed to the presence of uncontrolled factors associated with increased $\alpha$-T intake that might underlie the observed protective effects, in as much as the effect of uncontrolled confounders may well be of the same magnitude as the anticipated risk reduction with $\alpha$-T use. Therefore, more conclusive data obtained through randomized controlled trials should be taken into account before making definitive recommendations.

Surprisingly, in most of the intervention studies, no measurement was made of oxidative stress and, thus, it was impossible to conclude whether the interventions actually modified oxidative stress in the patients. Furthermore, the rate constant for the reaction of $\alpha$-T with $\mathrm{O}_{2}$ radicals is up to five orders of magnitude slower $\left(k=2.5 \times 10^{6} \mathrm{M}^{-1} \mathrm{~s}^{-1}\right)$ than the rate of reaction of $\mathrm{O}_{2}$ radicals with endogenous antioxidant enzymes and molecules such as superoxide dismutase (SOD) and NO. ${ }^{33}$ Because oral intake of $\alpha$-T only modestly increases its plasma and tissue levels, this slow rate of reaction with ROS means that $\alpha-T$, at the concentrations reached in tissue, is unlikely to affect biological outcomes. Rational evaluation of combination and novel antioxidant therapies seems desirable. Furthermore it is important to remember that much higher doses of these vitamins have been used in model systems than are administered in clinical trials. Moreover, differences in activity between synthetic and natural tocopherols used in different studies might account for the large discrepancies between their findings. Finally, as long as $\alpha-T$ is associated with the lipophilic/hydrophobic domains of lipoproteins and cell membranes, while ROS are generated in the cytosolic and extracellular compartments, the reaction between them is not always self-evident. Therefore, $\alpha-T$ form bioavailability in different intervention studies seems also to be a matter of concern, especially for cell signaling, as long as most of the reported anti-inflammatory effects of $\alpha$-T seem to be due to RRR- $\alpha-T$.

\section{Optimal dosing, duration, and timing of therapy}

With respect to vitamin $\mathrm{E}$ requirements for reducing total and cause-specific mortality, it is important to note that significant reductions in risk were observed as serum $\alpha$-T values increased from $9.1 \mathrm{mg} / \mathrm{L}(21 \mu \mathrm{mol} / \mathrm{L})$ to $\sim 13 \mathrm{mg} / \mathrm{L}(30 \mu \mathrm{mol} / \mathrm{L}){ }^{34}$ In general, serum $\alpha-T$ concentrations are poorly correlated with dietary vitamin E estimates and optimal dosing and duration of therapy have yet to be established. Further basic investigation will be necessary to clarify the potential multiple mechanisms through which antioxidant therapy impacts on the progression and clinical manifestations of coronary atherosclerosis because this will help us to formulate more rational "antioxidant" treatment strategies as well as better designed clinical trials. Optimal dosing, duration, and timing of therapy ought rest on a more thorough understanding of whether the primary effect is on lesion formation/progression versus some alteration of the intrinsic character of the plaque that renders it resistant to rupture, or alternatively, that the main impact of $\alpha-T$ is extrinsic to the lesion via effects on platelet adhesion/aggregation, the coagulation cascade, cell proliferation, or NO-dependent vasodilatation. For example, in the ATBC trial, ${ }^{35}$ daily treatment with $50 \mathrm{mg}$ of $\alpha$-T for five to eight years had no effect on the risk of death from coronary heart disease, 
despite the significant increase in the median level of $\alpha$ - $T$, from $28.5 \mu \mathrm{mol} / \mathrm{L}$ at baseline to $42.5 \mu \mathrm{mol} / \mathrm{L}$ at three months. In the CHAOS Study, a large reduction in the number of patients with nonfatal myocardial infarction after a median follow-up of 1.4 years of treatment with $\alpha$-T was found, concomitantly with a significant increase in the mean $\alpha$-T levels, from 34.2 to $51.1 \mu \mathrm{mol} / \mathrm{L}$ in patients receiving $400 \mathrm{IU}$ of vitamin $\mathrm{E}$ per day and to $64.5 \mu \mathrm{mol} / \mathrm{L}$ in patients receiving $800 \mathrm{IU}$ per day. ${ }^{14}$ Within the Health Professionals Follow-up Study (HPFS), a trend toward benefit was found with daily consumption of only $25 \mathrm{IU}$ but this protective effect did not achieve statistical significance until doses were as high as $100 \mathrm{IU} / \mathrm{d}$. Maximal benefit was seen at a dosing range of 100-249 IU/d, with no further decrease in risk detected in subjects taking $250 \mathrm{IU} /$ day. ${ }^{36}$ Similarly, the Nurses' Health Study (NHS) demonstrated a potential protective effect at doses under $100 \mathrm{IU} /$ day but with wide confidence intervals. In the majority of recently completed and ongoing interventional trials doses of at least $400 \mathrm{IU} / \mathrm{d}$ was considered appropriate. ${ }^{37}$ It seems that there might be a threshold dose of $\alpha$-T that might be effective, ie, $800 \mathrm{IU} / \mathrm{d}$. However, a definitive beneficial dose scheme of $\alpha$-T weighted over its possible toxicity has not been found until now. On the other hand, precautions regarding the safety of vitamin E, especially at higher doses, are important to bear in mind, as long as there several studies raised concerns about potential harmful effects caused by vitamin $\mathrm{E}$ supplementation, especially hemorrhagic stroke. ${ }^{35}$

With respect to duration of treatment, again it is difficult to establish a consensus. Both the HPFS and NHS did not observe a statistically significant benefit until after two years of $\alpha$-T supplementation. Among interventional trials, several smaller studies have demonstrated no risk reduction with shorter duration of therapy at much higher doses. CHAOS recently confirmed a delay of benefit until after 200 days of therapy. As noted previously, the ATBC trial, which employed a lower dose of $\alpha$-T, observed only a marginal effect, even with 4.7 years of treatment. There were not sufficient numbers of subjects in either HPFS or NHS taking $\alpha$-T supplements for an adequate duration to detect a significant time-dependent benefit of therapy beyond two years. However, a suggestive trend was evident in the HPFS. Finally, it is important to consider the effects of dietary $\alpha$-T alone. Within both the NHS and the HPFS, dietary $\alpha$-T (observed median, 7.7 IU/d; range, 6.3-100 IU/d) did not appear to have any protective effect, and thus it has been widely held that high-dose supplementation is necessary to achieve substantial benefit. Combining the data from all trials of $\alpha$-T indicates that such treatment has little effect on the risk of death or cardiovascular events, at least over a four-tosix-year period. Since the primary mechanism of these agents may be the prevention of new lesions, $\alpha$-T may have to be used for more than five years to have a demonstrable benefit.

It is possible that oxidant stress, while elevated, is a marginal player in the end points (usually myocardial infarction, persistent angina, stroke, and vascular death) measured in clinical trials and that ROS generation is more relevant to initiation of the process, rather than its culmination. Late lethal cardiovascular events, on the other hand, involve not only the development of the atherosclerotic plaque, but also plaque rupture, vasoconstriction, and local thrombosis, resulting in partial or total arterial obstruction. In contrast to the majority of studies linking antioxidants with decreased atherosclerosis in animals, most trials in humans were initiated when atherosclerosis was already established. Although in humans supplementation with lipid-soluble antioxidants protects LDL against ex vivo oxidation, prevention of the initiating events in atherosclerosis may not be the principal mechanism responsible for the reduction in the clinical manifestations of atherosclerosis that has been linked to higher antioxidant intake. In the subjects in the NHS and the HPFS, it is likely that atherosclerosis was already present, because autopsy data from other studies indicate that atherosclerotic lesions are already established in childhood. ${ }^{38}$ In the Cambridge Heart Antioxidant Study, all the subjects had radiographic evidence of atherosclerosis. Thus, any explanation of the epidemiologic results must address the issue of pre-existing atherosclerotic lesions. Antioxidants could limit the clinical expression of coronary artery disease by causing the regression or slowing the progression of coronary atherosclerotic lesions.

\section{The role of inflammation}

Chronic inflammation is known to play a pivotal role in the atherogenetic process, in interplay with oxidative stress. Recently, studies in patients with chronic inflammation provided evidence linking markers of inflammation and oxidative stress. ${ }^{39-42}$ Recently, solid evidence revealed that inflammation aggravates oxidative stress and vice versa, interactions which take place through activation of the transcription factor $\mathrm{NF}-\kappa \mathrm{B}$, a regulator of several genes implicated in atherogenesis, such as genes coding for intracellular adhesion molecule-1 (ICAM-1) and vascular cellular adhesion molecule-1 (VCAM-1) and cytokines. $\alpha$-T acetate and succinate have been shown to inhibit TNF- $\alpha$-induced $\mathrm{NF}-\kappa \mathrm{B}$ activation in vitro. Thus, $\alpha-\mathrm{T}$ has been shown to have beneficial effects in inhibiting monocyte-endothelial adhesion when incubated with either endothelial cells or monocytes, and it is very likely that following supplementation it partitions into both monocytes and endothelial cells, and its ability to 
reduce monocyte-endothelial cell adhesion is greater. Several groups have shown that $\alpha-T$ supplementation in humans has various anti-inflammatory effects both in vivo and in vitro, such as the decrease in C-reactive protein (CRP), plasminogen activator inhibitor-1 (PAI-1), inflammatory interleukins and cytokines, etc. Moreover, it is now known that patients with a state of chronic inflammation, such as ESRD patients, have an increased expression and function of leukocyte 5-LOX, ${ }^{43}$ the enzyme that regulates leukotriene synthesis but also lipid peroxidation, ROS production, mitochondrial damage, and leukocyte apoptosis, thereby providing a putative link between inflammation and oxidative stress.

\section{Lessons learnt from vitamin E-coated membrane dialyzers}

In line with $\alpha$-T supplementation studies, studies in ESRD patients on chronic hemodialysis with the use of vitamin $\mathrm{E}$ coated dialyzer membrane, a membrane anticipated to exert antioxidative effects through the in situ action of $\alpha$-T on the constituents of the blood that come in contact with it ${ }^{44,45}$ have shown various anti-inflammatory and antioxidative effects. ${ }^{46-60}$ It is interesting that these effects took place either in combination with an increase in the levels of plasma $\alpha$-T or not (Table 2), a finding which means that anti-inflammatory and antioxidative effects of $\alpha$-T are probably regulated not as much by its levels in the systemic circulation, but rather by other pharmacokinetic factors, such as the type of the $\alpha$-T molecule used, the form of the drug, the dosing, the duration of therapy or the special pharmacokinetic conditions encountered in specific patient subpopulations. Furthermore, we have preliminary data in ESRD patients showing that anti-inflammatory effects of vitamin E-coated membranes precede its antioxidative effects (unpublished data). In this case, the beneficial effects of the membrane-bound $\alpha$-T probably take place through the protection it provides to circulating leukocytes against their repeated activation by the otherwise bioincompatible synthetic dialysis membrane and the abatement of the inflammatory reaction might secondarily lead to the antioxidative effects of $\alpha$-T. As long as atherosclerosis is a chronic inflammatory process as well, these findings might point towards a probably selective or potentiated effectiveness of $\alpha$-T in patients with chronic inflammation and, to this extent it is interesting that none of the large randomized, controlled trials ever studied in separate patients with chronic inflammation.

\section{Indications and target of treatment}

It is also possible that the patients included in these trials were inappropriate for testing the hypothesis. One universal characteristic of all relevant studies is the lack of specific indications for the treatment with $\alpha$-T supplementation, apart for the high cardiovascular risk of the patients. In contrast with other medications expected to confer cardiovascular benefits, such as statins, $\alpha-\mathrm{T}$ has been given indiscriminately to all patients at high cardiovascular risk. Thus, while in all studies which found a benefit on the primary endpoint, a significant increase in the respective plasma antioxidant levels was reported, in the opposite, in only four of the seven negative studies were antioxidant levels reported. It is characteristic that no clinical trials hitherto have been performed in which patient inclusion was based on concrete criteria concerning markers of oxidative stress, even though patients who do not have increased oxidative stress would not be expected to benefit particularly from antioxidant therapy. The efficacy of exogenous antioxidants in in vitro systems as well as in several clinical studies was highly conditioned by the degree of depletion of the diverse repertoire of endogenous antioxidant defenses. Thus, inclusion of patients who did not exhibit evidence of oxidant stress in vivo presumably could have diluted the population susceptible to benefit and undermined the sample size calculations for the clinical trials. Furthermore, with respect to $\alpha$-T supplementation and LDL oxidation, there are responders and nonresponders, and this could explain the null results in certain studies. The form of $\alpha$-T might be crucial with regards to nonantioxidant effects. ${ }^{61}$ Although both RRR- and synthetic $\alpha$-T (all-rac- $\alpha-T)$ have been shown by various groups to decrease LDL oxidation, with respect to cell signaling and inflammation (inhibition of protein kinase- $\mathrm{C}$ and decreasing the release of pro-inflammatory cytokines), it might be crucial for $\alpha$-T to transfer from the plasma membrane to the cytosol. The importance of intracellular transfer of $\alpha$-T by tocopherol associated protein (TAPS) might play a pivotal role in this regard. Thus, as long as TAPS mutations have been implicated in other pathologies with vitamin $\mathrm{E}$ deficiency, ${ }^{62}$ nonresponding to vitamin E supplementation in the aforementioned trials (cardiovascular endpoints or biomarkers), might be attributed to mutations in TAPS and other relevant biomolecules that are important in orchestrating both the antioxidant and nonantioxidant effects of $\alpha-T$.

Moreover, although several studies included smokers who would be anticipated to be in a state of increased inflammation, actually no measure of biomarkers of inflammation was reported in any of the studies, and it has recently been shown that $\alpha$-T is indeed anti-inflammatory, reducing monocyte proinflammatory cytokines and high-sensitivity CRP levels. ${ }^{63,64}$ As long as there is solid evidence that chronic inflammation is a pivotal player in the atherogenetic process in interplay 
Table 2 Summarized results in studies of the antioxidative and anti-inflammatory effects of vitamin E-coated membrane dialyzers

\begin{tabular}{|c|c|c|c|c|}
\hline Authors & Duration & Patient number & Control membrane & Results \\
\hline Galli ${ }^{46}$ & 3 months & 15 & Cuprammonium & $\begin{array}{l}\text { - } \uparrow \text { Levels of vitamins } \mathrm{E} \text { and } \mathrm{C} \\
\text { - } \downarrow \text { Lipid peroxidosis } \\
\text { - } \downarrow \text { ROS and NO synthesis by leukocytes } \\
\text { - } \downarrow \text { Apoptosis of monocytes and U937 cells }\end{array}$ \\
\hline Mune $^{47}$ & 2 years & 25 & Cellulose & $\begin{array}{l}\text { - } \downarrow \text { MDA and oxLDL } \\
\text { - Reduced aorta calcification } \\
\text { - No effects on plasma vitamin E levels }\end{array}$ \\
\hline Girndt ${ }^{48}$ & 4 weeks & 21 & Hemophane/Polyamide & $\begin{array}{l}\text { - } \downarrow \text { Intradialytic IL-6 production } \\
\text { - } \uparrow \text { In vitro peripheral blood T-lymphocyte proliferation }\end{array}$ \\
\hline Tarng ${ }^{49}$ & 3-8 weeks & 24 & Various & $\begin{array}{l}\text { - } \downarrow \text { Oxidative damage of DNA (8-OHdG) } \\
\text { - } \downarrow \text { ROS synthesis by leukocytes } \\
\text { - } \uparrow \text { Levels of vitamin E }\end{array}$ \\
\hline Eiselt $^{50}$ & 3 months & 20 & Cellulose & $\begin{array}{l}\text { - } \downarrow \text { Intradialytic lipid peroxidation } \\
\text { - Long term } \downarrow \text { of TBARS levels }\end{array}$ \\
\hline Satoh $^{51}$ & 6 months & 18 & Cellulose & $\begin{array}{l}\text { - Suppression of intradialytic increase in MDA, AGE and 8-OHdG } \\
\text { - Long term } \downarrow \text { of MDA, AGE and 8-OHdG }\end{array}$ \\
\hline Clermont $^{52}$ & I month & 16 & Polyacrylonitrile & $\begin{array}{l}\text { - } \downarrow \text { Of oxidative stress ( } \uparrow \text { levels of vitamin C/stable AFR/vitamin } \\
\text { C ratio) } \\
\text { - } \downarrow \text { Of intradialytic leukocyte activation }\end{array}$ \\
\hline Tsuruoka $^{53}$ & 10 months & 10 & Hemophane & $\begin{array}{l}\text { - Long term } \downarrow \text { of LDL and peroxides } \\
\text { - Long term } \downarrow \text { of leukocytoopenia and intradialytic } \downarrow \text { of oxLDL } \\
\text { and MDA levels }\end{array}$ \\
\hline Usberti ${ }^{54}$ & 7 months & 10 & Various & $\begin{array}{l}\text { - } \downarrow \text { Of MDA-4HNE and oxLDL } \\
\text { - } \uparrow \text { Of vitamin E levels } \\
\text { - } \uparrow \text { Survival of red blood cells } \\
\text { - No changes in TAS and thiol levels }\end{array}$ \\
\hline Pertosa $^{55}$ & 3 months & 8 & Cellulose & $\begin{array}{l}\text { - Suppression of C5b-9 increase } \\
\text { - } \downarrow \text { Of iNOS expression and leukocyte JNK levels }\end{array}$ \\
\hline $\mathrm{Hara}^{56}$ & 12 months & 13 & Various & - $\downarrow$ Of oxLDL \\
\hline Betjes $^{57}$ & 8 weeks & 14 & $\begin{array}{l}\text { Hemophane/ } \\
\text { Polysulfone }\end{array}$ & $\begin{array}{l}\text { - } \downarrow \text { Monocyte expression of MHC-I, CD54, CD 40, CD86 and } \\
\text { ICAM-I } \\
\text { - } \uparrow \text { Lectin-induced T-lymphocyte proliferation }\end{array}$ \\
\hline Morimoto ${ }^{58}$ & 6 months & 16 & Polysulfone & - Long term $\downarrow$ of ADMA, oxLDL and MDA-LDL levels \\
\hline Baragettiti & 32 weeks & 8 & Cellulose & - $\downarrow$ Of AGE and pentosidine \\
\hline Libetta $^{60}$ & 12 months & 10 & Cellulose & $\begin{array}{l}\text { - } \downarrow \text { Production of IL-4, IL- I0 and IFN- } \gamma \text { by CD4+ monocytes } \\
\text { - } \downarrow \text { Production of IL- } 12 \text { and IL- } 18 \text { by peripheral blood monocytes } \\
\text { - } \uparrow \text { Levels of vitamin E } \\
\text { - } \downarrow \text { Plama NO levels }\end{array}$ \\
\hline
\end{tabular}

Abbreviations: LDL, low-density lipoproteins; ROS, reactive oxygen species; NO, nitric oxide; oxLDL, oxidized LDL; IL, interleukin; 8-OHdG, 8-hydroxydeoxyguanosine; TBARS, thiobarbituric acid reactive substances; AGE, advanced glycation end-products; AFR, ascorbyl free radicals; MDA-4HNE, malondialdehyde 4-hydroxynonenal; TAS, total antioxidant status; iNOS, inducible nitric oxide synthase; JNK, c-Jun N-terminal kinase; MHC, major histocombatibility complex; ICAM, intercellular adhesion molecule; ADMA, asymmetric dimethylarginine; IFN- $\gamma$, interferon- $\gamma$.

with oxidative stress, the benefits from the treatment could be observed in special patient populations, such as diabetics or ESRD patients, ie patients with high degrees of both oxidative stress and chronic inflammation. These concerns have not been taken into account in any of the major studies of $\alpha$-T benefits up to now and may be a crucial obstacle for the documentation of the real cardiovascular benefits which vitamin E probably confers in particular patients. As stated before, 5-LOX is one of the enzymes through which $\alpha$-T exerts its actions, ${ }^{65}$ and its increased expression and function in ESRD patients might represent one possible mechanism for a selective effect of $\alpha$-T in these patients, in resemblance to the greatest cardiovascular benefits that statins have been shown to exert selectively in patients with inflammation. ${ }^{66}$ Finally, of concern is the observation that $\alpha$-T has a dual function and can have in some cases pro-oxidative rather than antioxidative effects, ${ }^{67,68}$ a characteristic that increases even more the necessity for the application of solid indications for treatment.

\section{Conclusions}

Several in vitro and in vivo studies have provided solid evidence regarding the antiatherogenic effects of $\alpha$-T. 
The discrepancy between the findings in the observational and intervention studies could be well attributed to inherent difficulties in the study of the beneficial effects of $\alpha$-T but also to deficiencies in the design of the studies performed until now. Further even more prolonged studies especially in specific patient subpopulations, ie, patients with increased oxidative stress and/or chronic inflammation, with the use of more delicate determination of the oxidative status of the patients and probably more efficient pharmacologic forms, are warranted in order to permit a more accurate estimation of the cardiovascular efficacy of $\alpha$-T.

\section{Disclosures}

The authors report no conflicts of interest in this work.

\section{References}

1. Steinberg D. Oxidative modification of LDL and Atherogenesis. Circulation. 1997;95:1062-1071.

2. Esterbauer H, Gebicki J, Puhl H, Jurgens G. The role of lipid peroxidation and antioxidants in oxidative modification of LDL. Free Radic Biol Med. 1992;13:341-390.

3. Jha P, Flather M, Lonn E, Farkouh M, Yusuf S. The antioxidant vitamins and cardiovascular disease: a critical review of epidemiologic and clinical trial data. Ann Intern Med. 1995;123:860-872.

4. Gey KF, Puska P, Jordan P, Moser UK. Inverse correlation between plasma vitamin $\mathrm{E}$ and mortality from ischemic heart disease in crosscultural epidemiology. Am J Clin Nutr. 1991;53(1 Suppl):326S-334S.

5. Riemersma RA, Wood DA, Macintyre CC, Elton RA, Gey KF, Oliver MF. Risk of angina pectoris and plasma concentrations of vitamins A, C, and E and carotene. Lancet. 1991;337:1-5.

6. Singh RB, Ghosh S, Niaz MA, et al. Dietary intake, plasma levels of antioxidant vitamins, and oxidative stress in relation to coronary artery disease in elderly subjects. Am J Cardiol. 1995;76:1233-1238.

7. Mezzetti A, Zuliani G, Romano F, et al. Associazione Medica Sabin. Vitamin E and lipid peroxide plasma levels predict the risk of cardiovascular events in a group of healthy very old people. $J$ Am Geriatr Soc. 2001;49:533-537.

8. Armstrong BK, Mann JI, Adelstein AM, Eskin F. Commodity consumption and ischemic heart disease mortality, with special reference to dietary practices. J Chronic Dis. 1975;28:455-469.

9. Feki M, Souissi M, Mokhtar E, et al. Vitamin E and coronary heart disease in Tunisians. Clin Chem. 2000;46:1401-1405.

10. Verlangieri AJ, Kapeghian JC, el-Dean S, Bush M. Fruit and vegetable consumption and cardiovascular mortality. Med Hypotheses. 1985; $16: 7-15$.

11. Singh RB, Ghosh S, Niaz MA, et al. Dietary intake, plasma levels of antioxidant vitamins, and oxidative stress in relation to coronary artery disease in elderly subjects. Am J Cardiol. 1995;76:1233-1238.

12. Singh RB, Niaz MA, Rastogi SS, Rastogi S. Usefulness of antioxidant vitamins in suspected acute myocardial infarction (the Indian experiment of infarct survival-3). Am J Cardiol. 1996;77:232-236.

13. Rapola JM, Virtamo J, Haukka JK, et al. Effect of vitamin E and beta carotene on the incidence of angina pectoris. A randomized, doubleblind, controlled trial. JAMA. 1996;275:693-698.

14. Stephens NG, Parsons A, Schofield PM, Kelly F, Cheeseman K, Mitchinson MJ. Randomised controlled trial of vitamin E in patients with coronary disease: Cambridge Heart Antioxidant Study (CHAOS). Lancet. 1996;347:781-786.

15. Virtamo J, Rapola JM, Ripatti S, et al. Effect of vitamin E and beta carotene on the incidence of primary nonfatal myocardial infarction and fatal coronary heart disease. Arch Intern Med. 1998;158:668-675.
16. Yusuf S, Dagenais G, Pogue J, Bosch J, Sleight P. Vitamin E supplementation and cardiovascular events in high-risk patients. The Heart Outcomes Prevention Evaluation Study Investigators. $N$ Engl J Med. 2000;342:154-160.

17. De Gaetano G. Low-dose aspirin and vitamin $E$ in people at cardiovascular risk: a randomized trial in general practice. Collaborative Group of the Primary Prevention Project. Lancet. 2001;357:89-95.

18. Ylä-Herttuala S, Palinski W, Rosenfeld ME, et al. Evidence for the presence of oxidatively modified low density lipoprotein in atherosclerotic lesions of rabbit and man. J Clin Invest. 1989;84:1086-1095.

19. Steinberg D, Parthasarathy S, Carew TE, Khoo JC, Witztum JL. Beyond cholesterol: modifications of low-density lipoprotein that increase its atherogenicity. N Engl J Med. 1989;320:915-924.

20. Zingg JM, Azzi A. Non-antioxidant activities of vitamin E. Curr Med Chem. 2004;11:1113-1133.

21. Holvoet P. Endothelial dysfunction, oxidation of low-density lipoprotein, and cardiovascular disease. Ther Apher. 1999;3:287-293.

22. Verlangieri AJ, Bush MJ. Effects of d-alpha-tocopherol supplementation on experimentally induced primate atherosclerosis. $J$ Am Coll Nutr. 1992;11:131-138.

23. Prasad K, Kalra J. Oxygen free radicals and hypercholesterolemic atherosclerosis: Effect of vitamin E. Am Heart J. 1993;125:958-973.

24. Upston JM, Terentis AC, Morris K, Keaney Jr JF, Stocker R. Oxidized lipid accumulates in the presence of alpha-tocopherol in atherosclerosis. Biochem J. 2002;363:753-760.

25. Suarna C, Wu BJ, Choy K, et al. Protective effect of vitamin E supplements on experimental atherosclerosis is modest and depends on preexisting vitamin E deficiency. Free Radic Biol Med. 2006;41: 722-730.

26. Berr C, Richard MJ, Roussel AM, Bonithon-Kopp C; for the EVA study group. Systemic Oxidative Stress and Cognitive Performance in the Population-Based EVA Study. Free Radic Biol Med. 1998;24: 1202-1208.

27. Kritchevsky SB, Shimakawa T, Tell GS, et al. Dietary antioxidants and carotid artery wall thickness. The ARIC Study. Atherosclerosis Risk in Communities Study. Circulation. 1995;92:2142-2150.

28. Winder AF. Antioxidants, cholesterol, and ischaemic heart disease: CHAOS or confusion? J Clin Pathol. 1997;50:269-270.

29. Dietary supplementation with n-3 polyunsaturated fatty acids and vitamin E after myocardial infarction: results of the GISSI-Prevenzione trial. Gruppo Italiano per lo Studio della Sopravvivenza n'nfarto miocardico. Lancet. 1999;354:447-455.

30. Boaz M, Smetana S, Weinstein T, et al. Secondary prevention with antioxidants of cardiovascular disease in end-stage renal disease (SPACE): randomised placebo-controlled trial. Lancet. 2000;356: 1213-1218.

31. Eidelman RS, Hollar D, Hebert PR, Lamas GA, Hennekens CH. Randomized trials of vitamin $\mathrm{E}$ in the treatment and prevention of cardiovascular disease. Arch Intern Med. 2004;164:1552-1556.

32. Vivekananthan DP, Penn MS, Sapp SK, Hsu A, Topol EJ. Use of antioxidant vitamins for the prevention of cardiovascular disease: meta-analysis of randomised trials. Lancet. 2003;361:2017-2023.

33. Serbinova EA, Packer L. Antioxidant properties of $\alpha$-tocopherol. Methods Enzymol. 1994;234:354-366.

34. Wright ME, Lawson KA, Weinstein SJ, et al. Higher baseline serum concentrations of vitamin $\mathrm{E}$ are associated with lower total and causespecific mortality in the Alpha-Tocopherol, Beta-Carotene Cancer Prevention Study. Am J Clin Nutr. 2006;84:1200-1207.

35. The effect of vitamin $E$ and beta carotene on the incidence of lung cancer and other cancers in male smokers. The Alpha-Tocopherol, Beta Carotene Cancer Prevention Study Group. N Engl J Med. 1994;330:1029-1035.

36. Rimm EB, Stampfer MJ, Ascherio A, Giovannucci E, Colditz GA, Willett WC. Vitamin E consumption and the risk of coronary heart disease in men. N Engl J Med. 1993;328:1450-1456.

37. Stampfer MJ, Hennekens CH, Manson JE, Colditz GA, Rosner B, Willett WC. Vitamin E consumption and the risk of coronary disease in women. N Engl J Med. 1993;328:1444-1449. 
38. Napoli C, D'Armiento FP, Mancini FP, et al. Fatty streak formation occurs in human fetal aortas and is greatly enhanced by maternal hypercholesterolemia. Intimal accumulation of low density lipoprotein and its oxidation precede monocyte recruitment into early atherosclerotic lesions. J Clin Invest. 1997;100:2680-2690.

39. Kirmizis D. Inflammatory reaction and oxidative stress in patients on chronic haemodialysis. PhD Thesis. Thessaloniki, Greece; Aristotle University; 2009.

40. Oka H, Ikeda S, Koga S, Miyahara Y, Kohno S. Atorvastatin induces associated reductions in platelet P-selectin, oxidized low-density lipoprotein, and interleukin-6 in patients with coronary artery diseases. Heart Vessels. 2008;23:249-256.

41. Annuk M, Zilmer M, Lind L, Linde T, Fellström B. Oxidative stress and endothelial function in chronic renal failure. J Am Soc Nephrol. 2001;12:2747-2752.

42. Danielski M, Ikizler TA, McMonagle E, et al. Linkage of hypoalbuminemia, inflammation, and oxidative stress in patients receiving maintenance hemodialysis therapy. Am J Kidney Dis. 2003;42: 286-294.

43. Gallucci MT, di Villahermosa SM, Maccarrone M. Vitamin E, 5-lipoxygenase and oxidative stress in haemodialysis patients: facts, not fancies. Nephrol Dial Transplant. 2008;23:772-773.

44. Yang CC, Hsu SP, Wu MS, Hsu SM, Chien C-T. Effects of vitamin C infusion and vitamin E-coated membrane on hemodialysis-induced oxidative stress. Kidney Int. 2006;69:706-714.

45. Morena M, Cristol JP, Descomps B, Canaud B. Does vitamin E bound on dialysis membrane improve the LDL susceptibility to oxidation? Lessons from an in vitro model. Contrib Nephrol. 1999;127:128-138.

46. Galli F, Rovidati S, Chiarantini L, Campus G, Canestrari F, Buoncristiani U. Bioreactivity and biocompatibility of a vitamin E-modified multi-layer hemodialysis filter. Kidney Int. 1998;54:580-589.

47. Mune M, Yukawa S, Kishino M, et al. Effect of vitamin E on lipid metabolism and atherosclerosis in ESRD patients. Kidney Int. 1999;71(Suppl):S126-S129.

48. Girndt M, Lengler S, Kaul H, Sester U, Sester M, Khler H. Prospective crossiver trial of the influence of vitamin E-coated dialyzer membranes on T-cell activation and cytokine induction. Am J Kidney Dis. 2000; 35:95-104.

49. Tarng DC, Huang TP, Liu TY, Chen HW, Sung YJ, Wei YH. Effect of vitamin E-bonded membrane on the 8-hydroxy 2'-deoxyguanosine level in leukocyte DNA of hemodialysis patients. Kidney Int. 2000;58: 790-799.

50. Eiselt J, Racek J, Trefil L, Opatrny K Jr. Effects of a vitamin E-modified dialysis membrane and vitamin $\mathrm{C}$ infusion on oxidative stress in hemodialysis patients. Artif Organs. 2001;25:430-436.

51. Satoh M, Yamasaki Y, Nagake Y, et al. Oxidative stress is reduced by the long-term use of vitamin E-coated dialysis filters. Kidney Int. 2001; 59:1943-1950.

52. Clermont G, Lecour S, Cabanne JF, et al. Vitamin E-coated dialyzer reduces oxidative stress in hemodialysis patients. Free Radic Biol Med. 2001;31:233-241
53. Tsuruoka S, Kawaguchi A, Nishiki K, et al. Vitamin E-bonded hemodialyzer improves neutrophil function and oxidative stress in patients with end-stage renal failure. Am J Kidney Dis. 2002;39:127-133.

54. Usberti M, Gerardi G, Micheli A, et al. Effects of a vitamin E-bonded membrane and of glutathione on anemia and erythropoietin requirements in hemodialysis patients. $J$ Nephrol. 2002;15:558-564.

55. Pertosa G, Grandaliano G, Soccio M, Martino C, Gesualdo L, Schena FP. Vitamin E-modified filters modulate Jun N-terminal kinase activation in peripheral blood mononuclear cells. Kidney Int. 2002; 62:602-610.

56. Hara T, Takahashi N, Kiyomoto H, et al. Reduction of oxidized lowdensity lipoprotein by the long-term use of vitamin E-coated dialyzers in hemodialysis patients. Dial Transplant. 2004;33:197-207.

57. Betjes MG, Hoekstra FM, Klepper M, Postma SM, Vaessen LM. Vitamin E-coated dialyzer membranes downregulate expression of monocyte adhesion and co-stimulatory molecules. Blood Purif. 2004;22: 510-517.

58. Morimoto H, Nakao K, Fukuoka K, et al. Long-term use of vitamin E-coated polysulfone membrane reduces oxidative stress markers in haemodialysis patients. Nephrol Dial Transplant. 2005;20:2775-2782.

59. Baragetti I, Furiani S, Vettoretti S, et al. Role of vitamin E-coated membrane in reducing advanced glycation end products in hemodialysis patients: a pilot study. Blood Purif. 2006;24:369-376.

60. Libetta C, Zucchi M, Gori E, et al. Vitamin E-loaded dialyzer resets PBMC-operated cytokine network in dialysis patients. Kidney Int. 2004;65:1473-1481.

61. Singh U, Devaraj S. Vitamin E: inflammation and atherosclerosis. Vitam Horm. 2007;76:519-549.

62. Ouahchi K, Arita M, Kayden H, et al. Ataxia with isolated vitamin E deficiency is caused by mutations in the $\alpha$-tocopherol transfer protein. Nat Genet. 1995;9:141-145.

63. Singh U, Devaraj S, Jialal I. Vitamin E, oxidative stress, and inflammation. Annu Rev Nutr. 2005;25:151-174.

64. Devaraj S, Tang R, Adams-Huet B, et al. Effect of high-dose alphatocopherol supplementation on biomarkers of oxidative stress and inflammation and carotid atherosclerosis in patients with coronary artery disease. Am J Clin Nutr. 2007;86:1392-1398.

65. Taccone-Gallucci M, Manca-di-Villahermosa S, Battistini L, Stuffler RG, Tedesco M, Maccarrone M. N-3 PUFAs reduce oxidative stress in ESRD patients by inhibiting 5-lipoxygenase activity. Kidney Int. 2006;69:1450-1454.

66. Ridker PM, Pfeffer MA, Sacks F, Braunwald E. Long-term effects of pravastatin on plasma concentration of $\mathrm{C}$-reactive protein. The cholesterol and recurrent events (CARE) Investigators. Circulation. 1999; 100:230-235.

67. Bowry VW, Ingold KU, Stocker R. Vitamin E in human low-density lipoprotein. When and how this antioxidant becomes a pro-oxidant. Biochem J. 1992;288:341-344.

68. Stocker R. The ambivalence of vitamin E in atherogenesis. Trends Biochem Sci. 1999;24:219-223.
Vascular Health and Risk Management

\section{Publish your work in this journal}

Vascular Health and Risk Management is an international, peerreviewed journal of therapeutics and risk management, focusing on concise rapid reporting of clinical studies on the processes involved in the maintenance of vascular health; the monitoring, prevention and treatment of vascular disease and its sequelae; and the involvement of

\section{Dovepress}

metabolic disorders, particularly diabetes. This journal is indexed on PubMed Central and MedLine. The manuscript management system is completely online and includes a very quick and fair peer-review system, which is all easy to use. Visit http://www.dovepress.com/ testimonials.php to read real quotes from published authors. 